\title{
Emerging Targeted Strategies in Advanced Hepatocellular Carcinoma
}

\author{
Richard S. Finn, $\mathrm{MD}^{1}$ \\ 1 Division of Hematology/Oncology, David Geffen School of Medicine \\ at University of California Los Angeles, Los Angeles, California \\ Semin Liver Dis 2013;33(S1):S11-S19.

\begin{abstract}
Address for correspondence and reprint requests Richard S. Finn, MD, Division of Hematology/Oncology, David Geffen School of Medicine at University of California Los Angeles, 10833 Le Conte Ave, 11-934 Factor Bldg, Los Angeles, CA 90095 (e-mail: rfinn@mednet.ucla.edu).
\end{abstract}

\begin{abstract}
Keywords

- hepatocellular carcinoma

- brivanib

- angiogenesis inhibition

- mTOR inhibition

- combination therapy

Treatment of advanced-stage hepatocellular carcinoma (HCC) remains a challenge because of the complex nature of the disease and the lack of available therapies. The antiangiogenic multikinase inhibitor sorafenib is the first therapy to demonstrate a significant overall survival benefit in advanced HCC. However, new agents for both firstand second-line treatment of advanced HCC are needed. The multiple pathways involved in HCC oncogenesis, proliferation, and survival provide many opportunities for the development of molecularly targeted therapies. Many novel agents are under investigation in phase III trials in advanced HCC, including antiangiogenic multikinase inhibitors (e.g., brivanib, sunitinib, linifanib) and inhibitors of the mammalian target of rapamycin (mTOR) pathway (e.g., everolimus). Although these therapies have demonstrated some utility as single agents in advanced HCC, rational combinations of therapies are likely to provide greater success. Current research efforts are directed at combining agents targeting different molecular pathways (e.g., sorafenib in combination with erlotinib) and combining molecularly targeted agents with systemic chemotherapy or transarterial chemoembolization (TACE). Therapies targeting other molecular pathways in HCC are in early development; future research will focus on discovering additional targets for therapy and identifying biomarkers that predict the success of current therapies.
\end{abstract}

Hepatocellular carcinoma (HCC) is a complex and heterogeneous malignancy that arises in the context of progressive underlying liver dysfunction. Given the asymptomatic nature of early disease and the limited use of surveillance, the majority of HCC cases present at advanced or incurable stages. The prognosis of advanced-stage HCC is poor, with an overall survival (OS) rate of $<5 \%,{ }^{1}$ and in earlier stages, 5 -year recurrence rates of over $70 \%$ have been reported despite surgical or locoregional therapies. ${ }^{2-4}$ The treatment options for patients with recurrent or de novo advanced HCC are limited, and until recently there were no systemic treatment options that provided a clear survival benefit for these patients. Systemic chemotherapy and hormone therapies have not been effective in HCC, partly owing to the inherent hepatic dysfunction and the chemoresistance of the tumor., ${ }^{5,6}$ However, in the last decade, a better understanding of the molecular pathogenesis of HCC has led to the evaluation of molecular targeted therapies in this setting. Although the exact molecular mechanisms for hepatocarcinogenesis have still not been defined, angiogenesis has been found to have an integral role in HCC pathogenesis, making this a rational therapeutic target in this disease.

Sorafenib is an antiangiogenic multikinase inhibitor that targets the vascular endothelial growth factor receptor (VEGFR)-1, VEGFR-2, VEGFR-3, platelet-derived growth factor receptor- (PDGFR-) $\beta$, RAF kinase, and stem cell factor receptor (c-kit). It was the first systemic therapy to demonstrate a significant improvement in OS in patients with advanced HCC. Two positive pivotal phase III trials (the Sorafenib HCC Assessment Randomized Protocol [SHARP] trial and the AsiaPacific trial), and its subsequent approval represent a major breakthrough in the treatment of advanced HCC. ${ }^{7,8}$ However,
Issue Theme Enhancing Clinical Outcomes in Hepatocellular Carcinoma; Guest Editor, Ghassan Abou-Alfa, MD
Copyright @ 2013 by Thieme Medical Publishers, Inc., 333 Seventh Avenue, New York, NY 10001, USA. Tel: +1(212) 584-4662.
DOI http://dx.doi.org/ 10.1055/s-0033-1333632. ISSN 0272-8087. 
given the limitations of sorafenib therapy, such as resistance and tolerability, there are still unmet medical needs in the treatment of HCC. Our knowledge of the diverse etiologies and the genetic heterogeneity of HCC and the multiple molecular pathways implicated in HCC pathogenesis are now being evaluated as potential targets for therapeutic interventions, including the VEGF, fibroblast growth factor (FGF), PDGFR, epidermal growth factor receptor (EGFR), and mammalian target of rapamycin (mTOR) pathways. This review will examine our current understanding of these pathways, the efficacy and safety data pertaining to the most promising targeted agents beyond sorafenib, and novel treatment combinations in clinical testing for HCC. There are many other novel agents and targets in development, including histone deacetylase inhibitors (HDAC), c-Met inhibitors, MEK kinase inhibitors, insulin-like growth factor receptor (IGFR), arginine deiminase, and the anti-VEGF monoclonal antibody bevacizumab. In this article, we will focus on those agents currently in advanced phase III trials.

\section{Signaling Pathways Involved in HCC Pathogenesis}

Hepatocellular carcinoma is a highly vascularized tumor, and the central role of angiogenesis in its initiation, growth, and subsequent dissemination to other tissues is well recognized. Angiogenesis in HCC is dependent on endothelial cell activation, proliferation, and migration, which occur in response to angiogenic cues (e.g., hypoxia and inflammation) and involves several molecular effectors such as growth factors, extracellular matrix proteins, and proteases. ${ }^{9,10}$ Vascular endothelial growth factor and its receptors are known to be key mediators of HCC neovascularization, primarily through their stimulation of endothelial cell growth and induction of vascular permeability. ${ }^{9,10}$ Supporting the major role of VEGF in hepatocarcinogenesis are reports of its increased expression from low-grade to high-grade dysplastic nodules to early HCC, which correlates directly with increased neoangiogenesis and cell proliferation activity. ${ }^{11}$ Additionally, high serum levels of VEGF have been shown to significantly correlate with advanced tumor stage, recurrence of HCC following resection, and presence of intrahepatic metastasis and venous invasion. ${ }^{12}$ Overexpression of VEGF and its receptors in tumor tissue is also reportedly associated with worse OS and recurrence-free survival after surgical resection. ${ }^{13-15}$ Similarly, a prospective study showed that pretreatment serum elevations in VEGF were associated with progressive disease and poor survival in patients with inoperable HCC who underwent transarterial chemoembolization (TACE) treatment. ${ }^{16}$

In addition to the VEGF pathway, FGF and its family of receptors have been implicated also in augmenting HCC growth, invasion, and angiogenesis, making it an attractive candidate for therapeutic intervention. ${ }^{17}$ Activation of the FGF pathway induces neovascularization through various mechanisms, including stimulation of endothelial cell proliferation, migration, invasion, and capillary formation. ${ }^{18,19}$ Increased serum levels of FGF and concomitant activation of FGF receptors are associated with tumor invasion and recurrence, treatment resistance, and poor prognosis in HCC. $^{20,21}$ Synergistic interactions between FGF and VEGF have been shown to drive HCC development and angiogenesis. ${ }^{22,23}$ Compelling evidence indicates that induction of the FGF signaling pathways might represent a resistance mechanism to the antiangiogenic effects of VEGF-targeted agents in HCC. ${ }^{23,24}$ In addition, alterations in ligand expression has been identified as a potential driver in HCC. ${ }^{25}$ Together, these data indicate that concomitant inhibition of both the VEGF and FGF pathways might be more efficient at controlling disease and overcoming resistance to anti-VEGF therapies than targeting either factor alone.

Several other signaling pathways have been shown to be involved in HCC pathogenesis; the most studied are the phosphatidylinositol 3-kinase (PI3K)/Akt/mTOR, EGFR, Ras/ Raf/mitogen-activated protein kinase/ERK kinase (MEK)/ extracellular-signal-regulated kinase (ERK), and IGFR pathways. ${ }^{26}$ The PI3K/Akt/mTOR pathway is a major intracellular signaling cascade that is involved in the regulation of cell growth, proliferation, and survival. ${ }^{27}$ Mammalian target of rapamycin is a potent inducer of angiogenesis through upregulation of the hypoxia-induced gene HIF1- $\alpha{ }^{28}$ The mTOR pathway mediates its effects through activation of various tyrosine kinase receptors, such as VEGFR, EGFR, PDGFR, and IGFR. ${ }^{29}$ Nearly $50 \%$ of patients with HCC have shown activation of the mTOR pathway, which may be partially attributable to activation signals from receptor tyrosine kinases such as IGFR and/or EGFR pathways. ${ }^{30}$ The activation of the mTOR pathway in HCC is associated with aggressive tumor behavior and decreased survival, supporting efforts to target this pathway for therapeutic interventions. ${ }^{31}$ The Ras/Raf/MEK/ERK signaling cascade is another important intracellular pathway. Ras activation and subsequent downstream signaling may be mediated by hepatitis C virus (HCV) infection. As Raf is a potential target for sorafenib, this observation may be another explanation for sorafenib's clinical activity in HCC. ${ }^{32,33}$ In addition, the aberrant activation of the Wnt pathway may also play a role in HCC pathogenesis and is another potential target in HCC. ${ }^{34}$

cMET is a tyrosine kinase receptor, with its ligand hepatocyte growth factor (HGF), that has been implicated in liver cancer. Most recently, randomized phase II data of the cMET inhibitor, tivantinib, has demonstrated activity in a subset of patients with advanced HCC that have progressed on sorafenib and had elevated expression of cMET by immunohistochemistry. ${ }^{35}$

There has been considerable interest in targeting peptide growth factor signaling via the EGFR and IGFR axis, which is suggested by elevated levels of these receptors in HCC. ${ }^{36,37}$ The increasing awareness of the association of insulin resistance, diabetes, obesity, and nonalcoholic steatohepatitis (NASH) in the development of cirrhosis and HCC also is evidence that the IGFR pathway might have a causal role in this process. ${ }^{38}$ Given the molecular heterogeneity of HCC, the challenge is identifying in which patients any given alteration is critical. It is unlikely that any of these targeted agents will yield clinical success without selecting the patients whose tumors are most dependent on these pathways and therefore 


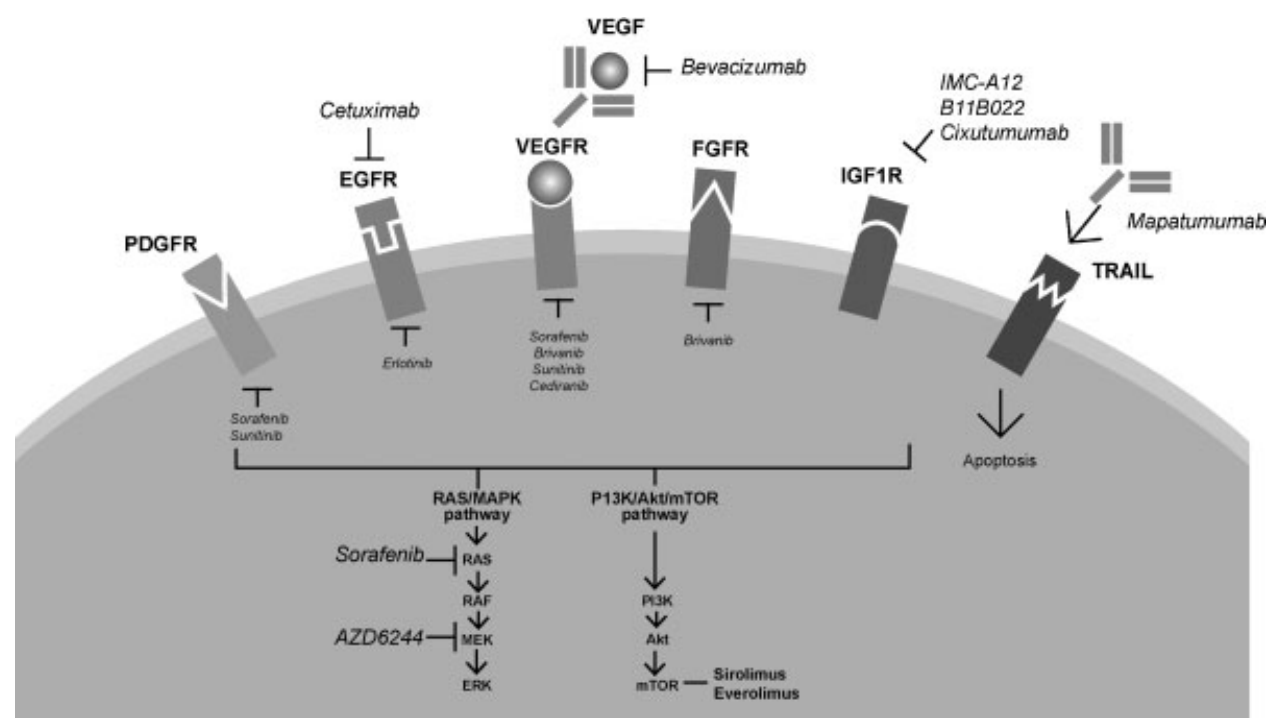

Fig. 1 Molecular targets and targeted agents in hepatocellular carcinoma. ${ }^{39}$ EGFR, epidermal growth factor receptor; ERK, extracellular-signalregulated kinase; FGFR, fibroblast growth factor receptor; HCC, hepatocellular carcinoma; MEK, mitogen-activated protein kinase/ERK kinase; mTOR, mammalian target of rapamycin; PDGFR, platelet-derived growth factor receptor; VEGF, vascular endothelial growth factor; VEGFR, VEGF receptor. (Reprinted with permission from Siegel B et al. Hepatology 2010;52:360-369. Copyright John Wiley and Sons).

most likely to benefit, and the identification of predictive markers of response is essential for successful development of new targeted agents.

\section{Emerging Molecular Therapies in Phase III Development}

There are currently a historic number of investigational agents being tested in HCC, most of which are targeting the previously described VEGF axis, FGF, EGFR, and mTOR signaling pathways (-Fig. 1). ${ }^{39}$ The most recent clinical data relating to these novel agents, their combinations, and ongoing trials are outlined in - Tables 1 and $\mathbf{2}^{35,40-65}$

\section{Sunitinib}

Similar to sorafenib, sunitinib is an oral, multitargeted inhibitor of several tyrosine kinases, such as VEGF-receptors, PDGFR, and c-KIT, which are involved in regulation of tumor growth, angiogenesis, and metastatic invasion. Sunitinib showed promising antitumor activity in phase II HCC studies, though there were significant toxicities seen, such as bone marrow suppression and a small number of grade 5 events. ${ }^{40,66}$ In addition, no one consistent dosing scheme was used in these studies. With this in mind, it may not be surprising that a phase III study comparing sunitinib to sorafenib in patients with advanced HCC was terminated early due to higher incidence of drug-related serious adverse events and failure to demonstrate noninferiority of OS benefit (median OS in the intent-to-treat population: 7.9 months vs 10.2 months; hazard ratio $[\mathrm{HR}]=1.30 ; 95 \%$ confidence interval $[\mathrm{CI}], 0.99-1.30$; $p=0.001) .{ }^{41}$ In an exploratory analysis, sorafenib substantially improved median OS in comparison to sunitinib in patients with HCV infection (17.6 months vs 9.2 months;
$\mathrm{HR}=1.52 ; 95 \% \mathrm{CI}, 1.09-2.13 ; p=0.0165)$, whereas in patients with HBV infection, both agents were equally effective ( 8.0 months vs 7.6 months; $\mathrm{HR}=1.10 ; 95 \% \mathrm{CI}$, $0.92-1.33 ; p=0.1714) .{ }^{41}$ Further analyses of this dataset are ongoing, but the increased toxicity profile of sunitinib as compared with sorafenib likely played an important role in the results.

\section{Brivanib}

Brivanib is a selective dual inhibitor of the FGF and VEGF receptors that is currently in late-stage clinical development. In preclinical models, brivanib was shown to decrease tumor growth and neovascularization, induce apoptosis, and decrease tumor cell proliferation. ${ }^{67}$ Brivanib entered several phase III studies including testing in patients with HCC in both the first-line and second-line settings. ${ }^{42,68}$ An initial phase II open-label study evaluated brivanib monotherapy in two patient cohorts with unresectable, locally advanced, or metastatic HCC; 55 patients received brivanib as first-line therapy and 46 patients received brivanib as second-line therapy (having received one prior regimen of antiangiogenic therapy). Patients that received first-line brivanib therapy had a median progression-free survival (PFS) of 2.7 months and a median OS of 10 months (-Table $\mathbf{1}$ ). ${ }^{42}$ The disease control rate was $47 \%$, including a complete response in 1 patient and partial responses in 3 patients; 22 patients achieved disease stabilization. As second-line therapy, brivanib therapy resulted in a tumor response rate of $4.3 \%$ (all partial responses) and a disease control rate of $45.7 \%$. Median OS was 9.8 months and the median time to progression (TTP) was 2.7 months. ${ }^{68}$ Most common grade $3 / 4$ adverse events (AEs) were fatigue and hypertension, which were experienced by $<17 \%$ of patients, while only $<2 \%$ experienced grade 3 hand-foot skin reactions. ${ }^{42,68}$ 
Table 1 Early efficacy results of novel targeted therapies in advanced development in hepatocellular carcinoma $35,40-51$

\begin{tabular}{|c|c|c|c|}
\hline Agent & Phase & $N$ & Efficacy \\
\hline Tivantinib $^{35}$ & $\begin{array}{l}\text { Randomized Phase II } \\
\text { Tivantinib vs placebo } \\
\text { ITT population } \\
\text { c-Met high }\end{array}$ & $\begin{array}{l}71 \text { vs } 36 \\
22 \text { vs } 15\end{array}$ & $\begin{array}{l}\text { Median TTP: } 6.9 \text { weeks vs } 6.0 \text { weeks } \\
\text { Median OS: } 6.6 \text { months vs } 6.2 \text { weeks } \\
\text { Median TTP: } 11.7 \text { weeks vs } 6.1 \text { weeks } \\
\text { Median OS: } 7.2 \text { months vs } 3.8 \text { weeks }\end{array}$ \\
\hline \multirow[t]{2}{*}{ Sunitinib } & Phase $\|^{40}$ & 34 & $\begin{array}{l}\text { Median PFS: } 3.9 \text { months } \\
\text { Median OS: } 9.8 \text { months }\end{array}$ \\
\hline & $\begin{array}{l}\text { Phase III } \\
\text { Sunitinib vs sorafenib }\end{array}$ & 1073 & Median OS: 7.9 vs 10.2 months; \\
\hline \multirow[t]{2}{*}{ Brivanib } & Phase $\|^{42}$ & 55 & $\begin{array}{l}\text { Median PFS: } 2.7 \text { months } \\
\text { Median OS: } 10 \text { months }\end{array}$ \\
\hline & $\begin{array}{l}\text { Phase III (BRISK-PS) } \\
\text { Brivanib vs placebo }\end{array}$ & 395 & $\begin{array}{l}\text { Median OS: } 9.4 \text { months vs } 8.3 \text { months } \\
\text { TTP: } 4.2 \text { months vs } 2.7 \text { months } \\
\text { RR: } 12 \% \text { vs } 2 \%\end{array}$ \\
\hline Linifanib $^{44}$ & Phase II & 44 & $\begin{array}{l}\text { TTP: } 5.4 \text { months } \\
\text { Median OS: } 10.4 \text { months }\end{array}$ \\
\hline \multirow[t]{3}{*}{ Erlotinib } & Phase $\|^{45}$ & 38 & Median OS: 13.0 months \\
\hline & Phase ${ }^{46}$ & 40 & Median OS: 10.8 months \\
\hline & $\begin{array}{l}\text { Phase III (SEARCH) } \\
\text { Sorafenib/erlotinib vs sorafenib/placebo }\end{array}$ & 362 & $\begin{array}{l}\text { Median OS: } 9.5 \text { months vs } 8.5 \text { months } \\
\text { TTP: } 3.2 \text { months vs } 4.0 \text { months }\end{array}$ \\
\hline Bevacizumab $^{48}$ & Phase II & 46 & $\begin{array}{l}\text { Median PFS: } 6.9 \text { months } \\
\text { Median OS: } 12.4 \text { months }\end{array}$ \\
\hline Ramucirumab ${ }^{49}$ & Phase II & 42 & $\begin{array}{l}\text { Median PFS: } 3.9 \text { months } \\
\text { Median OS: } 14.9 \text { months }\end{array}$ \\
\hline Everolimus $^{50}$ & Phase I/II & 20 & $\begin{array}{l}\text { Median PFS: } 3.8 \text { months } \\
\text { Median OS: } 8.4 \text { months }\end{array}$ \\
\hline Pegylated arginine deiminase $e^{51}$ & II & 80 & Mean OS: 15.8 months \\
\hline
\end{tabular}

Abbreviations: ITT, intent to treat; OS, overall survival; PFS, progression-free survival.

The promising results from the phase II study prompted the BRISK (Brivanib Study in Patients at Risk) HCC program that includes four large randomized phase III trials, three of which evaluate the role of brivanib in advanced HCC (BRISK-FL, BRISKPS, and BRISK-APS). ${ }^{55-57}$ The BRISK-PS trial evaluated brivanib versus placebo in 395 patients with Child-Pugh A or Child-Pugh B HCC for which prior sorafenib therapy had failed or who were intolerant to prior sorafenib therapy (NCT00825955). Although this study did not meet its primary end point of improving OS (9.4 months vs 8.2 months; $\mathrm{HR}=0.89 ; 95.8 \% \mathrm{CI}, 0.69-1.15$; $p=0.3307$ ), treatment with brivanib resulted in improvements in TTP (4.2 months vs 2.7 months; $\mathrm{HR}=0.56$; $95 \% \mathrm{CI}$, $0.42-0.78 ; p=0.0001)$ and response rate $(12 \%$ vs $2 \%$; odds ratio $=5.75 ; 95 \% \mathrm{CI}, 1.40-23.62 ; p=0.0032)$, which were secondary end points of the study. ${ }^{43}$ The toxicity profile of brivanib and median survival for the brivanib group were very similar to that seen in the phase II study in this population. What was surprising and unexpected in BRISK-PS was the median OS of 8.2 months in the control arm. This survival would not be expected based on data from the SHARP or AsiaPacific sorafenib studies. Although there were some baseline imbalances in the 2:1 randomized study that favored the control arm (significantly fewer patients with portal vein invasion versus the treatment group, $12 \%$ vs $25 \%$, respectively), this number also reflects the changing natural history of HCC in the postsorafenib era. Similar to the BRISK-PS study, the BRISKAPS trial is evaluating second-line brivanib in 252 patients of exclusively Asian ethnicity (NCT01108705). ${ }^{57}$ The BRISK-FL trial (NCT00858871) was directly comparing the clinical outcomes of brivanib versus sorafenib in 1050 patients with advanced HCC who received no prior systemic therapy. ${ }^{55}$ According to a July 2012 press release, this study did not meet its primary end point of OS. ${ }^{56}$

\section{Linifanib}

Linifanib is a potent multitargeted receptor tyrosine kinase inhibitor that selectively blocks the activity of the VEGFR and PDGFR families. Preclinical evidence indicates that linifanib inhibits tumor angiogenesis and vascular permeability in HCC experimental models. ${ }^{69}$ A phase II study was conducted in 44 patients with Child-Pugh A or Child-Pugh B liver disease to evaluate linifanib activity in advanced HCC in the first-line and second-line settings. ${ }^{44}$ Thirty-four percent of patients with Child-Pugh A liver function remained progression-free 
Table 2 Phase III trials in hepatocellular carcinoma ${ }^{52-65}$

\begin{tabular}{|c|c|c|c|}
\hline Study & Agent & Proposed accrual & Primary end point \\
\hline \multicolumn{4}{|l|}{ First-line therapy } \\
\hline $\begin{array}{l}\text { CALGB-80802 } \\
(\text { NCT01015833)52 }\end{array}$ & Sorafenib/doxorubicin vs sorafenib & 480 & OS \\
\hline $\begin{array}{l}\text { BOOST } \\
(\text { NCT01405573) }\end{array}$ & $\begin{array}{l}\text { Sorafenib vs placebo } \\
\text { (Child-Pugh B only) }\end{array}$ & 320 & OS \\
\hline $\begin{array}{l}\text { Linifanib } \\
(\text { NCT01009593) }\end{array}$ & Linifanib vs sorafenib & 900 & OS \\
\hline $\begin{array}{l}\text { BRISK-FLa } \\
(\text { NCT00858871) }\end{array}$ & Brivanib vs sorafenib & 1050 & OS \\
\hline \multicolumn{4}{|l|}{ Second-line therapy } \\
\hline $\begin{array}{l}\text { BRISK-APS } \\
(\text { NCT01108705) }\end{array}$ & Brivanib + BSC vs placebo + BSC & 252 & OS \\
\hline $\begin{array}{l}\text { EVOLVE-1 } \\
(\text { NCT01035229) }\end{array}$ & Everolimus + BSC vs placebo + BSC & 531 & OS \\
\hline $\begin{array}{l}\text { REACH } \\
(\text { NCT01140347) } 59\end{array}$ & Ramucirumab + BSC vs placebo + BSC & 544 & OS \\
\hline $\begin{array}{l}\text { POLARIS 2009-001 } \\
(\text { NCT01287585) }\end{array}$ & Pegylated arginine deiminase vs placebo & 633 & OS \\
\hline \multicolumn{4}{|c|}{ Adjuvant targeted therapy following surgical resection or local ablation } \\
\hline $\begin{array}{l}\text { STORM } \\
(\text { NCT00692770) }\end{array}$ & Sorafenib vs placebo & 1115 & RFS \\
\hline \multicolumn{4}{|c|}{ Targeted therapy in combination or following TACE } \\
\hline $\begin{array}{l}\text { ECOG } \\
(\text { NCT01004978)62 }\end{array}$ & Sorafenib/TACE ${ }^{\mathrm{b}}$ vs placebo/TACE & 400 & PFS \\
\hline $\begin{array}{l}\text { TACE-2 } \\
(\text { NCT01324076) }\end{array}$ & Sorafenib/DEB-TACE vs placebo/ DEB-TACE & 412 & PFS \\
\hline $\begin{array}{l}\text { BRISK-TA } \\
\left(^{(N C T 00908752)^{64}}\right.\end{array}$ & Brivanib vs placebo & 870 & OS \\
\hline $\begin{array}{l}\text { ORIENTAL } \\
\text { (NCT01465464) }^{65}\end{array}$ & Orantinib/TACE vs placebo/TACE & 880 & OS \\
\hline
\end{tabular}

Abbreviations: BSC, best supportive care; DEB-TACE, doxorubicin-eluting beads TACE; OS, overall survival; PFS, progression-free survival; RFS, recurrence-free survival; TACE, transarterial chemoembolization.

${ }^{a}$ Did not meet primary end point.

bACE might comprise doxorubicin, mitomycin, and cisplatin; doxorubicin alone; or doxorubicin-eluting beads.

at 16 weeks, with median TTP and OS of 5.4 months and 9.7 months, respectively. Overall survival was comparable to the results achieved in the SHARP study (median OS: 10.7 months). ${ }^{8}$ The most common grade $3 / 4$ AEs were hypertension (18\%), fatigue (14\%), and diarrhea (4.5\%). Based on these results, an ongoing randomized phase III study is investigating linifanib as first-line therapy in $>1000$ patients with Child-Pugh A advanced HCC (NCT01009593). ${ }^{54}$ Although final results are pending, this study was recently terminated by the independent data monitoring committee (IDMC).

\section{Ramucirumab}

Ramucirumab is a recombinant humanized antibody that specifically targets the extracellular domain of VEGFR2. In a phase II study of 42 patients with unresectable HCC who primarily presented with Child-Pugh A disease (74\%) and
Barcelona-Clinic Liver Cancer (BCLC) stage C (83\%), first-line ramucirumab therapy resulted in a disease control rate of $69 \% .{ }^{49}$ The median OS for all patients was 14.9 months, and in patients with BCLC C/Child-Pugh A and BCLC C/Child-Pugh B HCC, it was 18.0 months and 4.4 months, respectively. Grade 3/4 toxicities included gastrointestinal bleeding, hypertension, and fatigue. These results may indicate a signal of activity for ramucirumab in the front-line setting, though this was a relatively small population of clinically heterogeneous patients. Despite no clinical data supporting ramucirumab's activity in patients with HCC who have progressed on sorafenib, an ongoing randomized placebo-controlled phase III study (REACH) is evaluating second-line ramucirumab in comparison to best supportive care (BSC) following failure of prior sorafenib therapy in patients with Child-Pugh score $<7$ (NCT01140347). ${ }^{59}$ 


\section{Everolimus}

Mammalian target of rapamycin inhibitors, such as everolimus, have demonstrated antitumor activity in several malignancies. In HCC, two early clinical studies have shown that everolimus monotherapy was tolerable and had activity in patients who had received prior systemic therapy. ${ }^{50,70}$ Grade 3/4 AEs included lymphopenia, elevations in aspartate transaminase, and hyponatremia. In both studies, the median PFS and OS were 3.8 months and 8.4 months, respectively. Though both studies were single-arm and uncontrolled, their results suggested a potential clinical benefit with everolimus in both patients who had received prior sorafenib therapy and those who did not. An ongoing randomized, placebo-controlled, phase III clinical trial (EVOLVE-1) is evaluating everolimus plus BSC in patients with Child-Pugh A HCC pretreated with sorafenib (NCT01035229). ${ }^{58}$

\section{ADI-PEG 20}

ADI-PEG 20 is arginine deiminase (ADI) formulated with polyethylene glycol (PEG). Its potential as an anticancer agent is based on the hypothesis that HCC is deficient in argininosuccinate synthase and is, therefore, not capable of synthesizing arginine, and the relative arginine deficiency resulting from ADI is toxic to cancer cells. A randomized study comparing two doses of ADI-PEG-20 was performed in a heterogeneous population of patients. ${ }^{51}$ Median survival for all patients in this study was 15.8 months and the most common events in this study related to the drug include transient and reversible encephalopathy, skin irritation, or discomfort at the site of injection combined with low-grade fever. A phase III study of ADI-PEG-20 versus placebo in the second-line setting is ongoing (NCT01287585). ${ }^{60}$

\section{Combination Strategies}

Although single-agent therapy has demonstrated some success in the treatment of HCC, intensive research is now focused on enhancing the clinical benefit of many therapies through combination with other agents. The biologic rationale for combination approaches might involve targeting the same pathway at different points to achieve complete blockade of a given pathway or interrupting two different pathways simultaneously in hopes of circumventing feedback loops.

Based on potential interplay between angiogenesis and the EGFR signaling pathways, strategies targeting the VEGF and EGFR axis are being evaluated. In a single-arm, singleinstitution, phase II study of 40 patients with advanced HCC, erlotinib plus bevacizumab combination therapy was associated with a 16-week PFS of $62.5 \%$, median PFS of 9.0 months, and median OS of 15.65 months. ${ }^{71}$ Treatment-related grade $3 / 4$ toxicities were mostly reminiscent of those related to bevacizumab. Despite the lack of similar data with sorafenib and erlotinib, a large phase III study evaluating the combination was launched. However, recently presented results of the SEARCH trial (NCT00901901) demonstrated that the addition of erlotinib to sorafenib did not prolong OS ( $\mathrm{HR}=0.929$; $p=0.204$ ), which was the primary end point of the study. ${ }^{47} \mathrm{~A}$ phase I study evaluating the combination of everolimus and sorafenib as front-line therapy in advanced HCC did not move on to phase II development because of unexpected toxicity (thrombocytopenia), which prevented dose escalation of the mTOR inhibitor. ${ }^{72}$

Although the role of chemotherapy has not been defined in HCC, several strategies combining targeted and cytotoxic agents are being evaluated. In a randomized phase II trial of 96 patients with advanced HCC, most of whom had ChildPugh A liver disease, the combination of sorafenib plus doxorubicin as first-line therapy yielded a significant improvement in median OS, from 6.5 months to 13.7 months ( $\mathrm{HR}=0.49 ; 95 \% \mathrm{CI}, 0.3-0.8 ; p=0.006)$, and prolonged PFS (6.0 months vs 2.7 months; 95\% CI, 1.4-2.8; $p=0.006$ ) compared with doxorubicin alone. Though this study was launched prior to the results of the SHARP study, given sorafenib's proven single-agent activity, the more appropriate control arm would have been sorafenib alone, not doxorubicin. Toxicity profiles were similar to those observed with single agents; however, the combination of sorafenib/doxorubicin increased bone marrow suppression and all grade left ventricular dysfunction (19\% vs $2 \%$, respectively). ${ }^{73}$ Nevertheless, these results have led to an ongoing Cancer and Leukemia Group B (CALGB) phase III trial evaluating the superiority of sorafenib plus doxorubicin versus current standard of care, sorafenib, in a 480 patients with locally advanced or metastatic HCC (NCT01015833). ${ }^{74}$ Several single-arm studies combining bevacizumab with cytotoxic agents, including capecitabine, oxaliplatin/capecitabine, and gemcitabine/oxaliplatin, have shown modest clinical activity; however, bevacizumab-based combinations are not being pursued further in phase III studies at this time. ${ }^{75-77}$

As previously discussed in this supplement, surgical resection and local ablation are curative therapies for early-stage HCC, whereas TACE is the backbone of the management of patients with intermediate-stage HCC. Preclinical evidence indicates that TACE increases tumor hypoxic conditions, which then may elicit upregulation of proangiogenic factors, such as VEGF and FGF, and ultimately stimulate angiogenesis. ${ }^{78,79}$ It was found that patients with lower plasma VEGF levels following TACE have significantly longer survival compared with those with higher levels following TACE $(p=0.008) .{ }^{80}$ Taken together, these results suggest that coadministration of an antiangiogenic agents with TACE may block angiogenesis and prevent local recurrence and potentially distant metastasis. Several ongoing clinical trials are testing different combinations of TACE (or other locoregional therapies) and antiangiogenic agents. In a single-center phase II trial, combining TACE with doxorubicin-eluting beads (DEB-TACE) and sorafenib showed promising efficacy with a disease control rate of $95 \%$ and objective response of $58 \%{ }^{81}$ Toxicity was manageable and mostly related to sorafenib; however, the authors noted increased liver toxicity. Recently presented preliminary efficacy results from the multicenter, randomized, placebo-controlled phase II SPACE trial (Sorafenib or Placebo in Combination with TACE) are less impressive. This trial of 307 patients with intermediate-stage HCC randomized patients to a combination of DEB-TACE/sorafenib or DEB-TACE/ placebo and showed a trend toward better objective 
response (35.7\% vs $28.1 \%$ ), but did not significantly delay progression with sorafenib (TTP; HR $=0.797 ; 95 \% \mathrm{CI}, 0.588-$ $1.080 ; p=0.072) .{ }^{82} \mathrm{~A}$ similar phase III study of sorafenib in combination with TACE versus TACE alone performed in Japan and Korea likewise did not demonstrate any benefit with the combination. ${ }^{83}$ This approach is being further evaluated in two ongoing phase III trials (NCT01004978 and NCT01324076). ${ }^{62,63}$ Another important phase III trial in this population-with the primary end point of improving OS-BRISK-TA is investigating brivanib versus placebo as adjuvant therapy following TACE in 870 patients with intermediate HCC (NCT00908752). ${ }^{64}$ TSU-68 (orantinib) is an oral small molecule inhibitor of VEGFR, PDGFR, and FGFR also currently being evaluated in phase III study in combination with TACE vs TACE alone (NCT01465464). ${ }^{65}$

\section{Conclusion}

Hepatocellular carcinoma is a heterogeneous disease, both in regard to its clinical manifestation with underlying liver disease, and its complex pathogenesis involving aberrant signaling in several molecular pathways. The introduction of sorafenib in the treatment of advanced HCC saw a paradigm shift in its management. Based on new molecular knowledge and recognition of the limitations of sorafenib, novel molecular targeted therapies and combination strategies have been developed. Although early phase data with these agents have looked promising, to date nothing has been shown to be better than sorafenib in the front-line, and studies in the second-line have been disappointing. Looking ahead, concerted research efforts must be focused, not only on identifying new molecular targets and therapeutic agents, but also on understanding mechanisms of resistance to targeted agents. In addition to a better understanding of the natural history of HCC in the postsorafenib era, additional studies aimed at identifying predictive markers for response to novel agents are necessary. Incorporating these new agents into the presurgical or adjuvant setting also gives the opportunity for tissue collection and correlative science that is pivotal for increasing our understanding of these agents in HCC. Finally, the best method of assessing the activity of molecular targeted agents in HCC remains to be determined.

\section{Acknowledgments}

The author would like to thank Sabitha Muneer, PhD, Bojana Pajk, MD, MSc, Amy Furedy, RN, OCN, and Chelsey Goins, PhD, for their assistance in writing the manuscript, and Trudy Grenon Stoddert, ELS, for her editorial assistance and assistance preparing the manuscript for publication. Financial support was provided through an educational grant from Bristol-Myers Squibb Co.

\section{References}

1 Schütte K, Bornschein J, Malfertheiner P. Hepatocellular carcinomaepidemiological trends and risk factors. Dig Dis 2009;27(2):80-92
2 Imamura H, Matsuyama Y, Tanaka E, et al. Risk factors contributing to early and late phase intrahepatic recurrence of hepatocellular carcinoma after hepatectomy. J Hepatol 2003;38(2):200-207

3 Shirabe K, Kanematsu T, Matsumata T, Adachi E, Akazawa K, Sugimachi K. Factors linked to early recurrence of small hepatocellular carcinoma after hepatectomy: univariate and multivariate analyses. Hepatology 1991;14(5):802-805

4 Poon RT, Fan ST, Lo CM, Liu C-L, Wong J. Intrahepatic recurrence after curative resection of hepatocellular carcinoma: long-term results of treatment and prognostic factors. Ann Surg 1999; 229(2):216-222

5 Llovet JM, Bruix J; for the Barcelona-Clinic Liver Cancer Group. Systematic review of randomized trials for unresectable hepatocellular carcinoma: chemoembolization improves survival. Hepatology 2003;37(2):429-442

6 Marin JJG, Castaño B, Martinez-Becerra P, Rosales R, Monte MJ. Chemotherapy in the treatment of primary liver tumours. Cancer Ther 2008;6:711-728

7 Llovet JM, Ricci S, Mazzaferro V, et al; SHARP Investigators Study Group. Sorafenib in advanced hepatocellular carcinoma. N Engl J Med 2008;359(4):378-390

8 Cheng AL, Kang YK, Chen Z, et al. Efficacy and safety of sorafenib in patients in the Asia-Pacific region with advanced hepatocellular carcinoma: a phase III randomised, double-blind, placebo-controlled trial. Lancet Oncol 2009;10(1):25-34

9 Sanz-Cameno P, Trapero-Marugán M, Chaparro M, Jones EA, Moreno-Otero R. Angiogenesis: from chronic liver inflammation to hepatocellular carcinoma. J Oncol 2010;2010:272170

10 Semela D, Dufour J-F. Angiogenesis and hepatocellular carcinoma. J Hepatol 2004;41(5):864-880

11 Park YN, Kim Y-B, Yang KM, Park C. Increased expression of vascular endothelial growth factor and angiogenesis in the early stage of multistep hepatocarcinogenesis. Arch Pathol Lab Med 2000;124(7):1061-1065

12 Poon RT, Ng I-O, Lau C, et al. Serum vascular endothelial growth factor predicts venous invasion in hepatocellular carcinoma: a prospective study. Ann Surg 2001;233(2):227-235

13 Poon RT, Lau C, Pang R, Ng KK, Yuen J, Fan ST. High serum vascular endothelial growth factor levels predict poor prognosis after radiofrequency ablation of hepatocellular carcinoma: importance of tumor biomarker in ablative therapies. Ann Surg Oncol 2007; 14(6):1835-1845

14 Mas VR, Maluf DG, Archer KJ, Yanek KC, Fisher RA. Angiogenesis soluble factors as hepatocellular carcinoma noninvasive markers for monitoring hepatitis $C$ virus cirrhotic patients awaiting liver transplantation. Transplantation 2007;84(10):1262-1271

15 Poon RT, Ho JW, Tong CS, Lau C, Ng IO, Fan ST. Prognostic significance of serum vascular endothelial growth factor and endostatin in patients with hepatocellular carcinoma. Br J Surg 2004;91(10):1354-1360

16 Poon RT, Lau C, Yu WC, Fan ST, Wong J. High serum levels of vascular endothelial growth factor predict poor response to transarterial chemoembolization in hepatocellular carcinoma: a prospective study. Oncol Rep 2004;11(5):1077-1084

17 Hsu PI, Chow NH, Lai KH, et al. Implications of serum basic fibroblast growth factor levels in chronic liver diseases and hepatocellular carcinoma. Anticancer Res 1997;17(4A): 2803-2809

18 Basilico C, Moscatelli D. The FGF family of growth factors and oncogenes. Adv Cancer Res 1992;59:115-165

19 Presta M, Dell'Era P, Mitola S, Moroni E, Ronca R, Rusnati M. Fibroblast growth factor/fibroblast growth factor receptor system in angiogenesis. Cytokine Growth Factor Rev 2005;16(2): $159-178$

20 Uematsu S, Higashi T, Nouso K, et al. Altered expression of vascular endothelial growth factor, fibroblast growth factor-2 and endostatin in patients with hepatocellular carcinoma. J Gastroenterol Hepatol 2005;20(4):583-588 
21 Poon RT, Ng IO, Lau C, Yu WC, Fan ST, Wong J. Correlation of serum basic fibroblast growth factor levels with clinicopathologic features and postoperative recurrence in hepatocellular carcinoma. Am J Surg 2001;182(3):298-304

22 Yoshiji H, Kuriyama S, Yoshii J, et al. Synergistic effect of basic fibroblast growth factor and vascular endothelial growth factor in murine hepatocellular carcinoma. Hepatology 2002;35(4): 834-842

23 Huang X, Yu C, Jin C, et al. Ectopic activity of fibroblast growth factor receptor 1 in hepatocytes accelerates hepatocarcinogenesis by driving proliferation and vascular endothelial growth factorinduced angiogenesis. Cancer Res 2006;66(3):1481-1490

24 Bergers G, Hanahan D. Modes of resistance to anti-angiogenic therapy. Nat Rev Cancer 2008;8(8):592-603

25 Sawey ET, Chanrion M, Cai C, et al. Identification of a therapeutic strategy targeting amplified FGF19 in liver cancer by oncogenomic screening. Cancer Cell 2011;19(3):347-358

26 Kudo M. Signaling pathway and molecular-targeted therapy for hepatocellular carcinoma. Dig Dis 2011;29(3):289-302

27 Bjornsti MA, Houghton PJ. The TOR pathway: a target for cancer therapy. Nat Rev Cancer 2004;4(5):335-348

28 Treiber G. mTOR inhibitors for hepatocellular cancer: a forwardmoving target. Expert Rev Anticancer Ther 2009;9(2):247-261

29 Llovet JM, Bruix J. Molecular targeted therapies in hepatocellular carcinoma. Hepatology 2008;14:1312-1327

30 Villanueva A, Chiang DY, Newell P, et al. Pivotal role of mTOR signaling in hepatocellular carcinoma. Gastroenterology 2008; 135(6):1972-1983, e1-e11

31 Schmitz KJ, Wohlschlaeger J, Lang H, et al. Activation of the ERK and AKT signalling pathway predicts poor prognosis in hepatocellular carcinoma and ERK activation in cancer tissue is associated with hepatitis C virus infection. J Hepatol 2008;48(1):83-90

32 Abou-Alfa GK, Schwartz L, Ricci S, et al. Phase II study of sorafenib in patients with advanced hepatocellular carcinoma. J Clin Oncol 2006;24(26):4293-4300

33 Finn RS. Development of molecularly targeted therapies in hepatocellular carcinoma: where do we go now? Clin Cancer Res 2010;16(2):390-397

34 Boyault S, Rickman DS, de Reyniès A, et al. Transcriptome classification of HCC is related to gene alterations and to new therapeutic targets. Hepatology 2007;45(1):42-52

35 Rimassa L, Porta C, Borbath I, et al. Tivantinib (ARQ 197) versus placebo in patients (Pts) with hepatocellular carcinoma (HCC) who failed one systemic therapy: results of a randomized controlled phase II trial (RCT). J Clin Oncol 2012;30(Suppl): Abstract 4006

36 Ito Y, Takeda T, Sakon M, et al. Expression and clinical significance of erb-B receptor family in hepatocellular carcinoma. Br J Cancer 2001;84(10):1377-1383

$37 \mathrm{Wu}$ J, Zhu AX. Targeting insulin-like growth factor axis in hepatocellular carcinoma. J Hematol Oncol 2011;4:30-41

38 Siegel AB, Zhu AX. Metabolic syndrome and hepatocellular carcinoma: two growing epidemics with a potential link. Cancer 2009;115(24):5651-5661

39 Siegel AB, Olsen SK, Magun A, Brown RS Jr. Sorafenib: where do we go from here? Hepatology 2010;52(1):360-369

40 Zhu AX, Sahani DV, Duda DG, et al. Efficacy, safety, and potential biomarkers of sunitinib monotherapy in advanced hepatocellular carcinoma: a phase II study. J Clin Oncol 2009;27(18):3027-3035

41 Cheng A, Kang Y, Lin D, et al. Phase III trial of sunitinib (Su) versus sorafenib (So) in advanced hepatocellular carcinoma (HCC). J Clin Oncol 2011;29(suppl): Abstract 4000

42 Park JW, Finn RS, Kim JS, et al. Phase II, open-label study of brivanib as first-line therapy in patients with advanced hepatocellular carcinoma. Clin Cancer Res 2011;17(7):1973-1983

43 Llovet JM, Decaens T, Raoul J-L, et al. Brivanib versus placebo in patients with advanced hepatocellular carcinoma (HCC) who failed or were intolerant to sorafenib: results from the phase 3 BRISK-PS study. Abstract presented at: 47th Annual Meeting of the
European Association for the Study of the Liver; April 18-22, 2012; Barcelona, Spain

44 Toh H-C, Chen P-J, Carr BI, et al. Linifanib in advanced hepatocellular carcinoma (HCC): a phase 2 trial. Hepatology 2010;52 (Suppl 1): Abstract 1777

45 Philip PA, Mahoney MR, Allmer C, et al. Phase II study of erlotinib (OSI-774) in patients with advanced hepatocellular cancer. J Clin Oncol 2005;23(27):6657-6663

46 Thomas MB, Chadha R, Glover K, et al. Phase 2 study of erlotinib in patients with unresectable hepatocellular carcinoma. Cancer 2007;110(5):1059-1067

47 Zhu AX, Rosmorduc O, Evans J, et al. SEARCH: a phase III, randomized, double-blind, placebo-controlled trial of sorafenib plus erlotinib in patients with hepatocellular carcinoma (HCC). Ann Oncol 2012;23(Suppl 9): Abstract LBA2

48 Siegel AB, Cohen EI, Ocean A, et al. Phase II trial evaluating the clinical and biologic effects of bevacizumab in unresectable hepatocellular carcinoma. J Clin Oncol 2008;26(18):2992-2998

49 Zhu AX, Finn RS, Mulcahy MF, et al. A phase II study of ramucirumab as first-line monotherapy in patients with advanced hepatocellular carcinoma. J Clin Oncol 2010;28(15S): Abstract 4083

50 Zhu AX, Abrams TA, Miksad R, et al. Phase $1 / 2$ study of everolimus in advanced hepatocellular carcinoma. Cancer 2011;117(22): 5094-5102

51 Glazer ES, Piccirillo M, Albino V, et al. Phase II study of pegylated arginine deiminase for nonresectable and metastatic hepatocellular carcinoma. J Clin Oncol 2010;28(13):2220-2226

52 Phase III randomized study of sorafenib plus doxorubicin versus sorafenib in patients with advanced hepatocellular carcinoma (HCC). Available at: http://clinicaltrials.gov/ct2/ show/NCT01015833. Accessed January 11, 2012

53 Sorafenib in the first-line treatment of advanced hepatocellular carcinoma with Child-Pugh liver function class B: multicentre phase 3 randomized trial. Available at: http://clinicaltrials.gov/ cts/show/NCT01405573. Accessed January 11, 2012

54 An open-label, randomized phase 3 study of the efficacy and tolerability of linifanib (ABT-869) versus sorafenib in subjects with advanced hepatocellular carcinoma (HCC). Available at: http:// clinicaltrials.gov/ct2/show/NCT01009593. Accessed January 11, 2012

55 A randomized, double-blind multicenter phase III study of brivanib versus sorafenib as first-line treatment in patients with hepatocellular carcinoma (BRISK-FL). Available at: http://clinical trials.gov/ct2/show/NCT00858871. Accessed January 11, 2012

56 BRISK-FL study with investigational compound brivanib in hepatocellular carcinoma does not meet overall survival primary endpoint [press release]. Princeton, NJ: Bristol-Myers Squibb; July 19, 2012. Available at: http://www.reuters.com/article/ 2012/07/19/idUS218420+19-Jul-2012+BW20120719. Accessed July 20, 2012

57 A randomized, double-blind, multi-center phase III study of brivanib plus best supportive care (BSC) versus placebo plus BSC in Asian subjects with advanced hepatocellular carcinoma (HCC) who have failed or are intolerant to sorafenib (BRISK-APS). Available at: http://clinicaltrials.gov/ct2/show/NCT01108705. Accessed January 11, 2012

58 A randomized phase III, double-blind, placebo-controlled, multicenter study to evaluate the efficacy and safety of everolimus (RAD001) in adult patients with advanced hepatocellular carcinoma after failure of sorafenib treatment-The EVOLVE-1 Study. Available at: http://clinicaltrials.gov/ct2/show/NCT01035229. Accessed January 11, 2012

59 A multicenter, randomized, double-blind, phase 3 study of ramucirumab (IMC-1121B) drug product and best supportive care (BSC) versus placebo and BSC as second-line treatment in patients with hepatocellular carcinoma following first-line therapy with sorafenib (REACH). Available at: http://clinicaltrials.gov/ct2/show/ NCT01140347. Accessed January 11, 2012 
60 A DI-PEG 20 versus placebo in subjects with advanced hepatocellular carcinoma who have failed prior systemic therapy. Available at: http://clinicaltrials.gov/ct2/show/NCT01287585. Accessed September 25, 2012

61 A phase III randomized, double-blind, placebo-controlled study of sorafenib as adjuvant treatment for hepatocellular carcinoma after surgical resection or local ablation. Available at: http://clinical trials.gov/ct2/show/NCT00692770. Accessed February 23, 2012

62 A phase III randomized, double-blind trial of chemoembolization with or without sorafenib in unresectable hepatocellular carcinoma (HCC) in patients with and without vascular invasion. Available at: http://clinicaltrials.gov/ct2/show/NCT01004978. Accessed February 23, 2012

63 TACE-2. A randomized placebo-controlled, double blinded, phase III trial of sorafenib in combination with transarterial chemoembolization in hepatocellular cancer. Available at: http://clin icaltrials.gov/ct2/show/NCT01324076. Accessed February 23, 2012

64 A randomized, double-blind, multicenter phase III study of brivanib versus placebo as adjuvant therapy to trans-arterial chemoembolization (TACE) in patients with unresectable hepatocellular carcinoma (The BRISK TA Study). Available at: http://clinicaltrials. gov/ct2/show/NCT00908752. Accessed January 11, 2012

65 Orantinib in combination with transcatheter arterial chemoembolization in patients with unresectable hepatocellular carcinoma (ORIENTAL). Available at: http://clinicaltrials.gov/ct2/show/ NCT01465464. Accessed September 25, 2012

66 Faivre S, Raymond E, Boucher E, et al. Safety and efficacy of sunitinib in patients with advanced hepatocellular carcinoma: an open-label, multicentre, phase II study. Lancet Oncol 2009;10 (8):794-800

67 Huynh H, Ngo VC, Fargnoli J, et al. Brivanib alaninate, a dual inhibitor of vascular endothelial growth factor receptor and fibroblast growth factor receptor tyrosine kinases, induces growth inhibition in mouse models of human hepatocellular carcinoma. Clin Cancer Res 2008;14(19):6146-6153

68 Finn RS, Kang YK, Mulcahy M, et al. Phase II, open-label study of brivanib as second-line therapy in patients with advanced hepatocellular carcinoma. Clin Cancer Res 2012;18(7):2090-2098

69 Albert DH, Tapang P, Magoc TJ, et al. Preclinical activity of ABT-869, a multitargeted receptor tyrosine kinase inhibitor. Mol Cancer Ther 2006;5(4):995-1006

70 Blaszkowsky L, Abrams T, Miksad R, et al. Phase I/II study of everolimus in patients with advanced hepatocellular carcinoma. J Clin Oncol 2010;28(Suppl): Abstract e14542

71 Thomas MB, Morris JS, Chadha R, et al. Phase II trial of the combination of bevacizumab and erlotinib in patients who have advanced hepatocellular carcinoma. J Clin Oncol 2009;27(6): $843-850$
72 Finn RS, Poon TP, Yau T, et al. Phase I study of everolimus in combination with sorafenib in patients with advanced hepatocellular carcinoma (HCC). J Clin Oncol 2011;29(Suppl): Abstract 4074

73 Abou-Alfa GK, Johnson P, Knox JJ, et al. Doxorubicin plus sorafenib vs doxorubicin alone in patients with advanced hepatocellular carcinoma: a randomized trial. JAMA 2010;304(19):2154-2160

74 Phase III randomized study of sorafenib plus doxorubicin versus sorafenib in patients with advanced hepatocellular carcinoma (HCC). Available at: http://clinicaltrials.gov/ct2/show/NCT01015833. Accessed January 11, 2012

75 Hsu C-H, Yang T-S, Hsu C, et al. Efficacy and tolerability of bevacizumab plus capecitabine as first-line therapy in patients with advanced hepatocellular carcinoma. Br J Cancer 2010;102 (6):981-986

76 Sun W, Sohal D, Haller DG, et al. Phase 2 trial of bevacizumab, capecitabine, and oxaliplatin in treatment of advanced hepatocellular carcinoma. Cancer 2011;117(14):3187-3192

77 Zhu AX, Blaszkowsky LS, Ryan DP, et al. Phase II study of gemcitabine and oxaliplatin in combination with bevacizumab in patients with advanced hepatocellular carcinoma. J Clin Oncol 2006;24(12):1898-1903

78 Carmeliet P, Jain RK. Angiogenesis in cancer and other diseases. Nature 2000;407(6801):249-257

79 Li X, Feng G-S, Zheng C-S, Zhuo C-K, Liu X. Expression of plasma vascular endothelial growth factor in patients with hepatocellular carcinoma and effect of transcatheter arterial chemoembolization therapy on plasma vascular endothelial growth factor level. World J Gastroenterol 2004;10(19):2878-2882

80 Sergio A, Cristofori C, Cardin R, et al. Transcatheter arterial chemoembolization (TACE) in hepatocellular carcinoma (HCC): the role of angiogenesis and invasiveness. Am J Gastroenterol 2008;103 (4):914-921

81 Pawlik TM, Reyes DK, Cosgrove D, Kamel IR, Bhagat N, Geschwind JF. Phase II trial of sorafenib combined with concurrent transarterial chemoembolization with drug-eluting beads for hepatocellular carcinoma. J Clin Oncol 2011;29(30): 3960-3967

82 Lencioni R, Zou JM, Leberre M, et al. Sorafenib (SOR) or placebo $(\mathrm{PL})$ in combination with transarterial chemoembolization (TACE) with doxorubicin-eluting beads (DEBDOX) for intermediate-stage hepatocellular carcinoma: Phase II, randomized, double-blind SPACE trial. J Clin Oncol 2012;30(Suppl 4): Abstract LBA154

83 Okita K, Imanaka K, Chida N, et al. Phase III study of sorafenib in patients in Japan and Korea with advanced hepatocellular carcinoma (HCC) treated after transarterial chemoembolization (TACE). Abstract presented at the 2010 Gastrointestinal Cancers Symposium; January 22-24, 2010; Orlando, FL 